\title{
Association between Dietary Sodium and Potassium Intake with Chronic Kidney Disease in US Adults: A Cross-Sectional Study
}

\author{
Shailendra Sharma ${ }^{a}$ Kim McFann ${ }^{a} \quad$ Michel Chonchol $^{a} \quad$ lan H. de Boer ${ }^{c}$ \\ Jessica Kendrick ${ }^{a, b}$ \\ ${ }^{a}$ Division of Renal Diseases and Hypertension, University of Colorado Denver, and ${ }^{\mathrm{b}}$ Denver Health Medical Center, \\ Denver, Colo., and ' Division of Nephrology, University of Washington, Seattle, Wash., USA
}

\section{Key Words \\ Chronic kidney disease . Dietary sodium intake . \\ Dietary potassium intake}

\begin{abstract}
Background/Aims: Clinical guidelines recommend a diet low in sodium and high in potassium to reduce blood pressure and cardiovascular events. Little is known about the relationship between dietary sodium and potassium intake and chronic kidney disease (CKD). Methods: 13,917 participants from the National Health and Nutrition Examination Survey (2001-2006) were examined. Sodium and potassium intake were calculated from 24-hour recall and evaluated in quartiles. CKD was defined as estimated glomerular filtration rate (eGFR) $<60 \mathrm{ml} / \mathrm{min} / 1.73 \mathrm{~m}^{2}$ or eGFR $\geq 60 \mathrm{ml} / \mathrm{min} / 1.73 \mathrm{~m}^{2}$ with albuminuria ( $>30 \mathrm{mg} / \mathrm{g}$ creatinine). Results: The mean (SE) age and eGFR of participants were $45.0 \pm 0.4$ years and $88.0 \pm 0.60 \mathrm{ml} / \mathrm{min} / 1.73 \mathrm{~m}^{2}$, respectively. 2,333 (14.2\%) had CKD: $1,146(7.3 \%)$ had an eGFR $<60 \mathrm{ml} / \mathrm{min} / 1.73 \mathrm{~m}^{2}$ and 1,514 (8.4\%) had an eGFR $\geq 60 \mathrm{ml} / \mathrm{min} / 1.73 \mathrm{~m}^{2}$ and albuminuria. After adjustment for age, sex, race, BMI, diabetes, hypertension, cardiovascular disease and congestive heart failure, subjects in the highest quartile of sodium intake had lower odds of CKD compared to subjects in the lowest quartile (ad-
\end{abstract}

justed OR: $0.79 ; 95 \% \mathrm{Cl}: 0.66-0.96 ; \mathrm{p}<0.016)$. Compared to the highest quartile, the odds of CKD increased $44 \%$ for participants in the lowest quartile of potassium intake (adjusted OR: $1.44 ;$; $95 \mathrm{Cl}: 1.16-1.79 ; p=0.0011)$. Conclusions: Higher intake of sodium and potassium is associated with lower odds of CKD among US adults. These results should be corroborated through longitudinal studies and clinical trials designed specifically to examine the effects of dietary sodium and potassium intake on kidney disease and its progression.

Copyright $\odot 2013$ S. Karger AG, Base

\section{Introduction}

Chronic Kidney Disease (CKD) is an epidemic and a worldwide public health problem. The prevalence of CKD in the USA alone has increased from $10 \%$ during the period 1988-1994 to $13.1 \%$ during the period 1999-2004 [1]. The increasing incidence and prevalence can be attributed to changing demographics of the general population coupled with earlier detection of CKD. However, increases in the prevalence of obesity, diabetes [2-4] and hypertension [5, 6], known traditional cardiovascular risk factors, account for most of the increase in the prevalence of CKD. The presence of kidney disease is associ-

\section{KARGER}

E-Mail karger@karger.com

www.karger.com/ajn
(C) 2013 S. Karger AG, Basel

$0250-8095 / 13 / 0376-0526 \$ 38.00 / 0$
Jessica Kendrick, MD

Division of Renal Diseases and Hypertension

University of Colorado Denver, Denver Health Medical Center

660 Bannock St., Mail Code 4000, Denver, CO 80204 (USA)

E-Mail Jessica.Kendrick@ucdenver.edu 
ated with higher morbidity and mortality and increased health care utilization. Control of blood pressure, strict glycemic control and blocking of the renin-angiotensinaldosterone axis are some of the proven strategies in preventing and slowing the progression of CKD [7-11]. However, in most cases, even with adoption of these strategies, the incidence and prevalence of CKD continues to rise. Thus, the strategy of adopting traditional risk factor modifications alone is not sufficient. This emphasizes the need for different therapeutic targets, such as dietary sodium and potassium intake, to prevent CKD and slow its progression.

Extrapolations from observational studies and intervention trials suggest that population-wide moderation of sodium intake and increase of potassium intake might reduce cardiovascular events and prevent the onset of high blood pressure. The National Heart, Lung, and Blood Institute (NHLBI) promote the DASH (Dietary Approaches to Stop Hypertension) diet for the prevention and of control hypertension. The DASH diet has targets of 2,300 and 4,700 $\mathrm{mg}$ for sodium and potassium, respectively, and is rich in fruits, vegetables and low-fat dairy foods with reduced amounts of saturated fat, total fat and cholesterol. The blood pressure lowering effects of the DASH diet are seen in subjects with high normal blood pressure as well as with established hypertension [12]. Because risk factors for cardiovascular disease (CVD) and CKD often overlap, it is tempting to speculate that lower sodium and higher potassium intake may also be protective against kidney disease and kidney disease progression. However, the relationship between dietary sodium and potassium intake and CKD has not been examined in the general US population. We performed a cross-sectional study using the National Health and $\mathrm{Nu}$ trition Examination Survey (NHANES; 2001-2006) and included 13,917 participants to test the hypothesis that high dietary sodium intake and low dietary potassium intake is associated with increased odds of CKD in US adults.

\section{Methods}

\section{Study Population}

The NHANES is a population-based survey designed to collect information on the health and nutrition of adults and children in the US, and is unique in that it combines interviews and physical examinations. A stratified multistage sampling design was used, with an oversampling of African-Americans, Hispanics and persons over the age of 60 in order to produce reliable statistics. In this analysis, we used data from 31,507 participants from NHANES
2001-2006. Data were weighted using the dietary weights as described in the statistical analysis for the NHANES data. Participants were excluded if they did not have positive weights for the analysis $(n=3,243)$, if they lacked data on sodium intake, potassium intake and urinary albumin excretion, or were missing data for the calculation of estimated glomerular filtration rate (eGFR) by the abbreviated Modification of Diet in Renal Disease formula (MDRD) [13] ( $\mathrm{n}=14,397)$. The final sample used in this study included 13,917 adult participants.

\section{Primary Predictor and Outcome}

The primary predictor or independent variables were dietary sodium and potassium intake. Dietary sodium and potassium intake were specifically calculated from 24-hour dietary recalls that were requested from all NHANES examinees. All dietary interviews were conducted at the mobile examination centers using an in-person mode of interview. Data were collected on individual foods and total nutrient intake twice by trained dietary interviewers fluent in Spanish and English. Each mobile examination center examination room contained a standard set of measuring guides. These measuring guides were used to help the participant estimate portion sizes. Information on added salt (frequency and type) was obtained apart from detailed descriptions about food reported (i.e. type, form, brand name, amount consumed) and nutrients from each food.

The primary outcome of interest was CKD defined as eGFR $<60 \mathrm{ml} / \mathrm{min} / 1.73 \mathrm{~m}^{2}$ or eGFR $\geq 60 \mathrm{ml} / \mathrm{min} / 1.73 \mathrm{~m}^{2}$ with albuminuria. eGFR was calculated using the four-variable MDRD equation [13]. Albuminuria was assessed by the urinary albuminto-creatinine ratio and was defined as a ratio of $>30 \mathrm{mg} / \mathrm{g}$ creatinine. Subjects with a GFR $\geq 60 \mathrm{ml} / \mathrm{min} / 1.73 \mathrm{~m}^{2}$ were only classified as CKD if they had albuminuria. The eGFR $<60 \mathrm{ml} / \mathrm{min} / 1.73 \mathrm{~m}^{2}$ category included all subjects with an eGFR $<60 \mathrm{ml} / \mathrm{min} / 1.73 \mathrm{~m}^{2}$ regardless of whether they had albuminuria.

\section{Baseline Demographic and Clinical Data}

Questionnaire data included self-reported age and gender. Race/ethnicity was broken into four categories: non-Hispanic White, non-Hispanic Black, Mexican-American and other. CVD and congestive heart failure (CHF) were self-reported by participants. CHF was diagnosed if the participant reported ever being told by a physician they had CHF. CVD was diagnosed if participants reported being told by a doctor they have coronary heart disease, angina, a heart attack or stroke. Hypertension was diagnosed if the participant was taking antihypertensive medications, reported being told by a physician that they have high blood pressure, or the average of three blood pressure readings was a systolic blood pressure $>140 \mathrm{~mm} \mathrm{Hg}$ or a diastolic blood pressure $>90 \mathrm{~mm} \mathrm{Hg}$. Systolic and diastolic blood pressure was measured in a standard fashion. Participants were defined as having diabetes when they reported taking medication for diabetes, had a fasting glucose concentration $\geq 126 \mathrm{mg} / \mathrm{dl}$ (to convert to SI units multiply by 0.05551 ) or reported being told by a physician that they have diabetes. BMI was calculated as the weight in kilograms divided by the square of height in meters.

\section{Statistical Analysis}

For the purpose of this analysis, dietary sodium and potassium intake was examined in quartiles. Quartiles of sodium intake 1-4 were $\leq 2,116,2,117-3,061,3,062-4,267$ and $>4,267 \mathrm{mg}$ /day, re- 
Table 1. Baseline characteristics of study participants across quartiles of dietary sodium intake

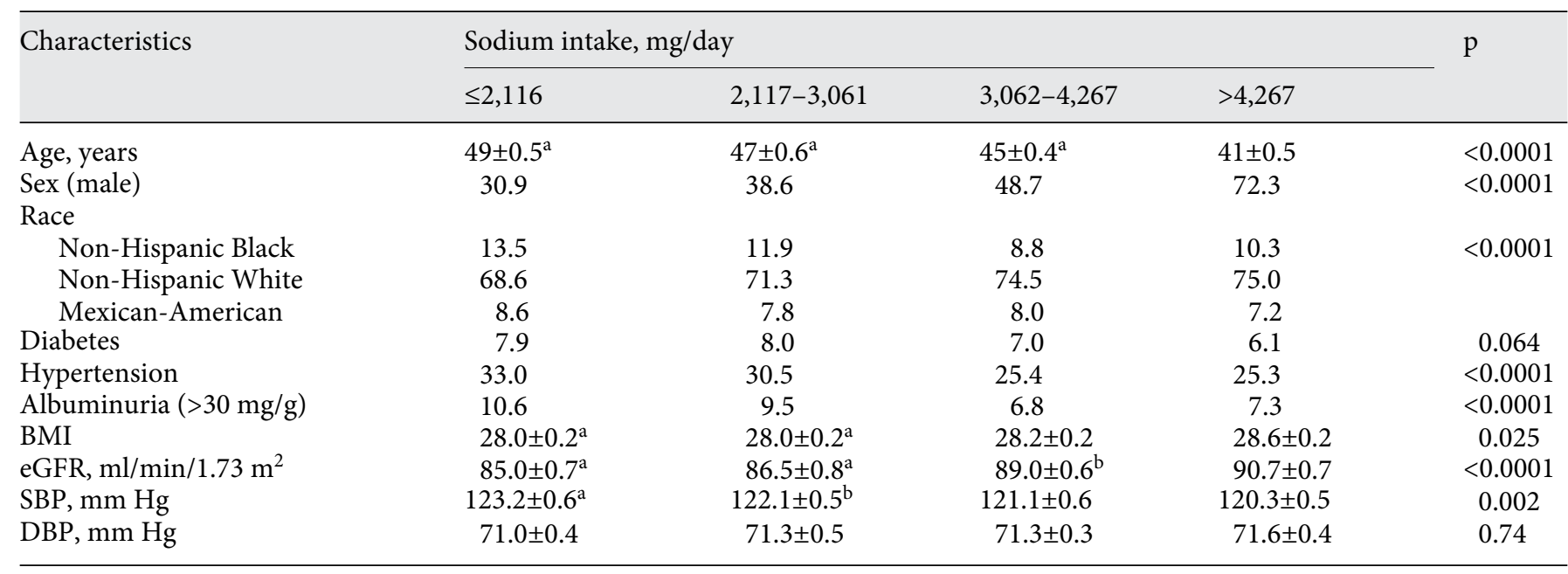

Values are expressed as means $\pm \mathrm{SE}$ or percentages. $\mathrm{SBP}=$ Systolic blood pressure; $\mathrm{DBP}=$ diastolic blood pressure. ${ }^{\mathrm{a}} \mathrm{p}<0.001$ compared to the 4 th quartile. ${ }^{b} \mathrm{p}<0.05$ compared to the 4 th quartile.

spectively, and quartiles of potassium intake $1-4$ were $\leq 1,737$, $1,738-2,455,2,456-3,341$ and $>3,342 \mathrm{mg} /$ day, respectively. For this analysis, the lowest quartile was used as the reference group for sodium intake and the highest quartile was used as the reference group for potassium intake. Demographic and clinical data were compared across quartiles of dietary sodium and potassium intake through the use of a $\chi^{2}$ test for categorical data and ANOVA for continuous variables. Multivariate logistic regression models were used to examine the association between sodium and potassium intake and CKD. We considered a priori variables that may be associated with dietary sodium and potassium intake and CKD as potential confounders in multivariate models. To permit the most useful interpretation of our results in addition to unadjusted models, we used the following concentrations of adjustment. Model 1 included age, gender, race/ethnicity, BMI, diabetes and hypertension status. Model 2 included covariates in model 1 plus CHF and CVD. We also examined the relationship of combinations of sodium and potassium intake with CKD. Median intake of sodium and potassium were used to determine 'high' and 'low' intake. Four groups of sodium and potassium intake were defined as follows: high sodium/high potassium intake, high sodium/low potassium intake, low sodium/high potassium intake and low sodium/low potassium intake. Two-tailed values of $\mathrm{p}<0.05$ were considered statistically significant. All statistical analyses were performed with SAS software, version 9.13 (SAS Institute, Cary, N.C., USA).

\section{Results}

\section{Baseline Characteristics}

The mean (SE) age and eGFR of the participants were $45.0 \pm 0.4$ years and $88.0 \pm 0.60 \mathrm{ml} / \mathrm{min} / 1.73 \mathrm{~m}^{2}$, respectively. The mean (SE) dietary sodium and potassium in-

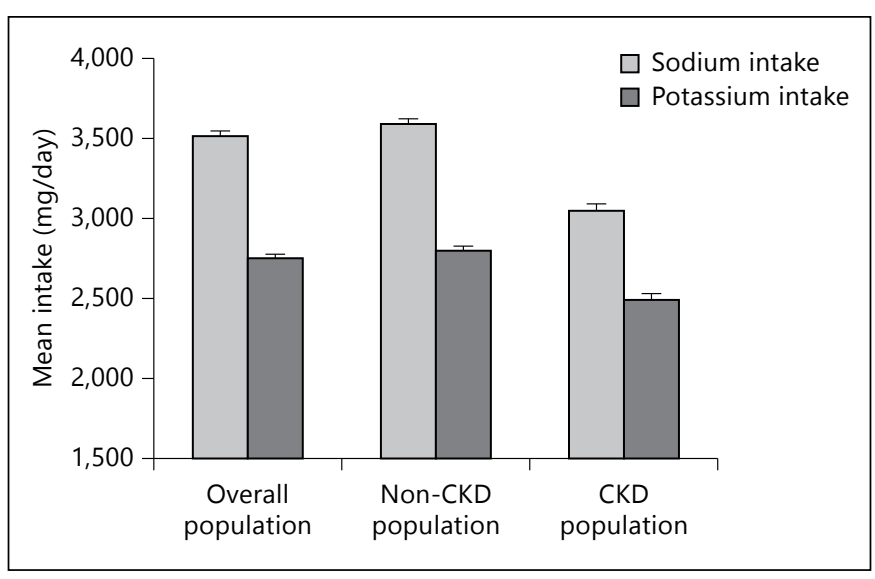

Fig. 1. Mean dietary sodium and potassium intake in study participants.

take were $3,520 \pm 26 \mathrm{mg} /$ day and $2,760 \pm 22 \mathrm{mg} /$ day, respectively (fig. 1). In this cohort, 2,333 (14.2\%) had CKD: $1,146(7.3 \%)$ had an eGFR $<60 \mathrm{ml} / \mathrm{min} / 1.73 \mathrm{~m}^{2}$ and 1,514 (8.4\%) had albuminuria $\geq 30 \mathrm{mg} / \mathrm{g}$. Among those with albuminuria, 1,187 had a GFR $\geq 60 \mathrm{ml} / \mathrm{min} / 1.73 \mathrm{~m}^{2}$. Of the patients with CKD, the mean (SE) dietary sodium and potassium intake were $3,053 \pm 40 \mathrm{mg} /$ day and 2,495 \pm $34 \mathrm{mg} /$ day, respectively (fig. 1). Baseline characteristics of the participants across dietary sodium and potassium intake are shown in tables 1 and 2, respectively. Participants in the highest quartile of sodium intake were more likely to be younger, be male, have a lower prevalence of hyper- 
Table 2. Baseline characteristics of study participants across quartiles of dietary potassium intake

\begin{tabular}{|c|c|c|c|c|c|}
\hline \multirow[t]{2}{*}{ Characteristics } & \multicolumn{4}{|c|}{ Potassium intake, $\mathrm{mg} /$ day } & \multirow[t]{2}{*}{$\mathrm{p}$} \\
\hline & $\leq 1,737$ & $1,738-2,455$ & $2,456-3,341$ & $>3,342$ & \\
\hline Age, years & $44 \pm 0.50$ & $47 \pm 0.5^{\mathrm{a}}$ & $47 \pm 0.5^{\mathrm{a}}$ & $44 \pm 0.5$ & $<0.0001$ \\
\hline Sex (male) & 29.5 & 41.7 & 50.8 & 68.5 & $<0.0001$ \\
\hline \multicolumn{6}{|l|}{ Race } \\
\hline Non-Hispanic Black & 17.7 & 12.2 & 8.0 & 7.3 & \multirow[t]{3}{*}{$<0.0001$} \\
\hline Non-Hispanic White & 65.3 & 69.3 & 76.7 & 77.3 & \\
\hline Mexican-American & 7.7 & 8.3 & 7.3 & 8.2 & \\
\hline Diabetes & 6.9 & 8.7 & 7.2 & 6.1 & 0.002 \\
\hline Hypertension & 30.3 & 31.0 & 28.3 & 24.3 & $<0.0001$ \\
\hline Albuminuria (>30 mg/g) & 10.1 & 9.7 & 7.3 & 7.0 & $<0.0001$ \\
\hline BMI & $28.6 \pm 0.2$ & $28.3 \pm 0.2$ & $28.2 \pm 0.3$ & $27.8 \pm 0.2^{b}$ & 0.006 \\
\hline $\mathrm{eGFR}, \mathrm{ml} / \mathrm{min} / 1.73 \mathrm{~m}^{2}$ & $89.1 \pm 0.7$ & $87.4 \pm 0.8$ & $87.2 \pm 0.7$ & $88.4 \pm 0.7$ & 0.056 \\
\hline $\mathrm{SBP}, \mathrm{mm} \mathrm{Hg}$ & $121.6 \pm 0.6$ & $122.9 \pm 0.6^{\mathrm{c}}$ & $122.0 \pm 0.5^{\mathrm{d}}$ & $120.3 \pm 0.4$ & 0.007 \\
\hline $\mathrm{DBP}, \mathrm{mm} \mathrm{Hg}$ & $70.8 \pm 0.4$ & $71.2 \pm 0.4$ & $71.6 \pm 0.4$ & $71.6 \pm 0.3$ & 0.22 \\
\hline
\end{tabular}

Values are expressed as means \pm SE or percentages. $\mathrm{SBP}=$ Systolic blood pressure; $\mathrm{DBP}=$ diastolic blood pressure. ${ }^{\mathrm{a}} \mathrm{p}<0.001$ compared to the 1 st quartile. ${ }^{\mathrm{b}} \mathrm{p}<0.05$ compared to the 1 st quartile. ${ }^{\mathrm{c}} \mathrm{p}<0.001$ compared to the 4 th quartile. ${ }^{\mathrm{d}} \mathrm{p}<0.05$ compared to the 4 th quartile.

Table 3. OR ( $95 \% \mathrm{CI})$ of CKD by quartiles of dietary sodium intake

\begin{tabular}{lllll}
\hline Sodium intake, mg/day & $\leq 2,116$ & $2,117-3,061$ & $3,062-4,267$ & $>4,267$ \\
\hline Unadjusted & 1.00 (ref.) & $0.77(0.66-0.90)$ & $0.52(0.44-0.61)$ & $0.46(0.40-0.53)$ \\
Model 1 & 1.00 (ref.) & $0.84(0.71-0.99)$ & $0.67(0.54-0.82)$ & $0.77(0.64-0.92)$ \\
Model 2 & 1.00 (ref.) & $0.85(0.71-1.02)$ & $0.68(0.55-0.85)$ & $0.79(0.66-0.96)$ \\
\hline
\end{tabular}

Model 1: adjusted for age, sex, race/ethnicity, BMI, diabetes and hypertension. Model 2: adjusted for covariates in model 1 plus CHF and CVD.

tension and albuminuria, have lower systolic blood pressure, and have a higher BMI and eGFR than participants in the lower quartiles of sodium intake (table 1). Participants in the highest quartile of potassium intake were more likely to be younger; be male; have a lower prevalence of hypertension, diabetes and albuminuria, and have lower BMI and lower systolic blood pressure than participants in the lower quartiles of potassium intake (table 2).

\section{Dietary Sodium and Potassium Intake and CKD}

The logistic regression analysis examining the relationship between sodium intake and CKD is shown in table 3. In unadjusted analysis, higher sodium intake was associated with decreased odds of CKD. Subjects with sodium intake in the highest quartile had $54 \%$ decreased odds of CKD compared to subjects in the lowest quartile.
After adjusting for age, sex, race, BMI, diabetes, hypertension, CVD and CHF, higher sodium intake was still associated with decreased odds of CKD. Participants with sodium intake in the second, third and fourth quartiles had 15, 32 and $21 \%$ lower odds of CKD compared to subjects with sodium intake in the lowest quartile. The odds of CKD did not change when subjects with CHF were excluded or when subjects with macroalbuminuria (urine albumin-to-creatinine ratio $>300 \mathrm{mg} / \mathrm{g}$ ) were excluded (data not shown). The relationship between dietary potassium intake and CKD is shown in table 4. In unadjusted analysis, participants in the first and second quartiles of potassium intake had increased odds of CKD compared to participants in the highest quartile. After adjustment for age, sex, race, BMI, diabetes, hypertension, CVD and CHF, subjects in the lowest quartile of potassium intake still had $44 \%$ increased odds 
Table 4. OR (95\% CI) of CKD by quartiles of dietary potassium intake

\begin{tabular}{lllll}
\hline Potassium intake, mg/day & $\leq 1,737$ & $1,737-2,455$ & $2,455-3,341$ & $>3,342$ \\
\hline Unadjusted & $1.72(1.39-2.12)$ & $1.59(1.30-1.94)$ & $1.22(1.00-1.49)$ & 1.00 (ref.) \\
Model 1 & $1.51(1.20-1.88)$ & $1.21(0.98-1.49)$ & $1.01(0.81-1.27)$ & 1.00 (ref.) \\
Model 2 & $1.44(1.16-1.79)$ & $1.19(0.97-1.46)$ & $1.00(0.80-1.24)$ & 1.00 (ref.) \\
\hline
\end{tabular}

Model 1: adjusted for age, sex, race/ethnicity, BMI, diabetes and hypertension. Model 2: adjusted for covariates in model 1 plus CHF and CVD.

Table 5. OR (95\% CI) of CKD by combinations of dietary sodium and potassium intake

\begin{tabular}{lllll}
\hline $\begin{array}{l}\text { Sodium and } \\
\text { potassium intake }\end{array}$ & $\begin{array}{l}\text { Low sodium/ } \\
\text { low potassium }\end{array}$ & $\begin{array}{l}\text { Low sodium/ } \\
\text { high potassium }\end{array}$ & $\begin{array}{l}\text { High sodium/ } \\
\text { low potassium }\end{array}$ & $\begin{array}{l}\text { High sodium/ } \\
\text { high potassium }\end{array}$ \\
\hline Unadjusted & 1.00 (ref.) & $0.82(0.68-0.98)$ & $0.59(0.47-0.74)$ & $0.50(0.43-0.57)$ \\
Model 1 & 1.00 (ref.) & $0.76(0.63-0.92)$ & $0.79(0.60-1.04)$ & $0.68(0.57-0.80)$ \\
Model 2 & 1.00 (ref.) & $0.77(0.64-0.94)$ & $0.83(0.61-1.06)$ & $0.70(0.59-0.83)$ \\
\hline
\end{tabular}

Model 1: adjusted for age, sex, race/ethnicity, BMI, diabetes and hypertension. Model 2: adjusted for covariates in model 1 plus CHF and CVD.

of CKD compared to participants in the highest quartile (adjusted OR: 1.44; 95\% CI: 1.16-1.79; $\mathrm{p}=0.0011$ ). The second and third quartiles of potassium intake were not associated with increased odds of CKD. The odds of CKD did not change when subjects with CHF or macroalbuminuria were excluded from the analysis (data not shown). Results were unchanged when diuretic use was included in the fully adjusted model (results not shown). When the association of dietary sodium and potassium intake was examined with eGFR $<60 \mathrm{ml} / \mathrm{min} /$ $1.73 \mathrm{~m}^{2}$ and eGFR $\geq 60 \mathrm{ml} / \mathrm{min} / 1.73 \mathrm{~m}^{2}$ with microalbuminuria as separate dependent variables, the association of dietary sodium and potassium intake was only present with eGFR $<60 \mathrm{ml} / \mathrm{min} / 1.73 \mathrm{~m}^{2}$ (results not shown).

We also examined the relationship of combinations of potassium and sodium intake with CKD (table 5). The median intake of sodium $(3,061 \mathrm{mg} /$ day $)$ and potassium $(2,455 \mathrm{mg} /$ day $)$ were used to determine high and low sodium and potassium intake. Regardless of the sodium intake, after multivariate adjustment, subjects with high potassium intake had decreased odds of CKD compared to subjects with low potassium intake. Subjects with high potassium and high sodium intake had the lowest odds of CKD (OR: 0.70; 95\% CI: 0.59-0.83; p < 0.0001), whereas subjects with high potassium and low sodium intake also had decreased odds of CKD (OR: 0.77; 95\% CI:
$0.63-0.94 ; \mathrm{p}=0.01$ ). The combination of high sodium intake with low potassium intake was not associated with CKD. We also evaluated a serum sodium-hypertension and sodium-diabetes interaction term in the final adjusted model for CKD. Similarly, we also examined a serum potassium-hypertension and potassium-diabetes interaction for CKD. Results of the association between sodium and potassium with odds of CKD were similar irrespective of hypertension or diabetes mellitus status ( $p$ for interaction $>0.20$ for all).

\section{Discussion}

In this cross-sectional study of 13,917 participants from NHANES 2001-2006, we found higher dietary intakes of both sodium and potassium to be associated with lower odds of CKD. To our knowledge, this is the first study examining the association between dietary sodium and potassium intake and CKD in the general US population.

Experimental data suggests that sodium intake may be an important risk factor for kidney disease. Sodium may be nephrotoxic directly by increasing oxidative stress and indirectly by increasing blood pressure and attenuating the effects of renin-angiotensin-aldosterone system (RAAS) blockers. Several rat studies have shown in- 
creased oxidative stress in the renal cortex and vascular beds in response to increased dietary salt intake [14-16]. These same experimental models also showed a benefit of sodium restriction on progression of kidney disease. High sodium consumption has also been shown to result in decreased renal blood flow and increased glomerular pressure, GFR and filtration fraction [17]. Major consequences of these changes in renal hemodynamics are an increase in urinary protein excretion and progression of kidney disease [18]. Furthermore, studies have found that high sodium intake is linked to increased proteinuria and kidney disease progression [19-21]. Increased sodium intakes also affect the therapeutic response to antihypertensive agents in patients with salt-sensitive hypertension. For example, inhibitors of the RAAS reduce intraglomerular pressure, which in turn decreases proteinuria and the risk for progression of kidney disease. Increased sodium intake abolishes these salutary effects of RAAS inhibitors. In a randomized controlled trial comparing the effect of enalapril to the calcium channel blocker isradipine on blood pressure control, patients treated with enalapril had a more significant reduction in blood pressure while consuming a low-salt rather than a high-salt diet [22]. Similarly, despite the blood pressure lowering effect of the DASH diet, the largest reductions in blood pressure were obtained by a lower-salt version of the DASH diet [12]. A recent subgroup analysis of 1,177 diabetic patients from the Reduction of Endpoints in NIDDM with the Angiotensin II Antagonist Losartan (RENAAL) and Irbesartan Diabetic Nephropathy (IDNT) trials found a significantly reduced risk of renal events in patients on an angiotensin receptor blocker with a low dietary sodium intake [23]. Thus, existing studies suggest that higher sodium consumption may be an important risk factor for CKD and CKD progression, but data regarding the effect of sodium intake on kidney disease is scarce.

In our study, we found that a high-sodium diet was associated with lower odds of CKD. These findings were unexpected as we hypothesized that a high-sodium diet would be associated with a higher risk of CKD. It is possible that those with a known history of CKD were following a low-sodium diet. Prior studies have demonstrated that most people with CKD are unaware of this diagnosis, but the mean dietary sodium intake in the patients with CKD in our cohort was $3,053 \pm 40 \mathrm{mg} /$ day compared to $3,597 \pm 26 \mathrm{mg} /$ day in subjects without CKD $(\mathrm{p}<0.0001)$. Alternatively, it is possible that a low-sodium diet may be a risk factor for CKD. In a study of patients with type 1 diabetes and macroalbuminuria, low sodium intake was associated with an increased risk of end-stage renal disease [24]. There is evidence that low sodium intake may result in reflex activation of the sympathetic nervous system, RAAS and metabolic pathways that lead to increases in total and low-density lipoprotein cholesterol [25]. Activation of these pathways may mitigate otherwise beneficial effects of lower-sodium diets on blood pressure, kidney disease and kidney disease progression. To date, no interventional studies have examined the effect of sodium restriction on the development or progression of CKD.

Our study also showed that low dietary potassium intake was strongly associated with CKD. Several studies have shown an inverse relationship between dietary potassium intake and blood pressure, and low potassium intake is considered a major contributor to the prevalence of hypertension [26-30]. Several studies have indicated that a diet high in potassium reduces blood pressure levels [23-30]. In the International Study of Salt and Blood Pressure (INTERSALT), an increment in potassium intake from 1,173 to $1,564 \mathrm{mg}$ was associated with a drop in systolic blood pressure by $2-3 \mathrm{~mm} \mathrm{Hg}$ [31]. In a meta-analysis of studies examining the effects of potassium intake on blood pressure, increased potassium intake resulted in a greater reduction of blood pressure in hypertensive patients (3.5-mm Hg decrease in systolic blood pressure) compared to normotensive patients $(0.97-\mathrm{mm} \mathrm{Hg}$ decrease in systolic blood pressure) [32]. Thus, high dietary potassium intake may be protective for CKD through decreases in blood pressure. Alternatively, high dietary potassium intake may be protective for CKD through nonblood pressure pathways as in our study the association of potassium intake with CKD was independent of hypertension. Further studies are needed to elucidate the mechanisms by which high dietary potassium intake may be protective for CKD.

The combined activity of sodium and potassium in the diet may play an important biologic role as the urinary sodium-to-potassium ratio is a stronger predictor of blood pressure and cardiovascular events than urinary sodium or potassium excretion alone [25]. A higher sodium-to-potassium ratio in the diet is associated with higher blood pressure and a higher risk of CVD. We found that regardless of sodium intake, a high potassium intake was protective for CKD. Interestingly, the group with both high potassium and high sodium intake had the greatest reduction in risk of CKD. The reason for this is unclear, but previous studies have found that potassium may lower blood pressure more in the presence of high dietary sodium intake. For example, in a meta-analysis of 
trials examining the effect of potassium supplementation on blood pressure, the blood pressure lowering effect of increased potassium intake was greater in subjects consuming a diet high in sodium [30]. Interventional trials are needed to determine if high dietary potassium intake reduces the risk of CKD.

Our study has several limitations worth noting. First, since this is an observational study, a causal relationship between the dietary intake of sodium and potassium with CKD cannot be established. Second, we used dietary recall data to determine sodium and potassium intake as urinary sodium and potassium excretion was not available. A 24-hour urinary sodium and potassium excretion is the gold standard for measuring dietary sodium and potassium intake as dietary recall methods tend to underestimate sodium intake due to difficulty characterizing the sodium content of foods, especially in foods eaten away from home and in the amount of sodium added in cooking [33]. However, some of these problems with dietary recall surveys can be overcome by using a highquality survey methodology and detailed information on the sodium content of food, which is what the NHANES survey did. Several studies have utilized the dietary recall data from NHANES to estimate sodium and potassium intake and relate these intakes to meaningful clinical outcomes [34-36]. Despite the argument that a 24-hour dietary recall gives an imprecise estimation of actual consumption, a uniform underestimation or overestimation of actual dietary intake by the 24 -hour recall should not differentially bias the results. Third, dietary sodium and potassium intake may be linked to broader patterns of food consumption and it may be these foods that are responsible for observed relationships. Fourth, variability of diet across different ethnic groups could have caused residual confounding by race/ethnicity. Finally, it is pos- sible that participants with a known history of CKD were following a low-sodium diet. However, the mean sodium intake in the population with CKD was still $>3,000 \mathrm{mg}$ daily and the mean eGFR of the population was $88.0 \pm$ $0.60 \mathrm{ml} / \mathrm{min} / 1.73 \mathrm{~m}^{2}$. Thus, it is likely that many of these subjects who met our definition for CKD were not aware of this diagnosis.

Notwithstanding these limitations, the present study also has several strengths. To our knowledge this is the first study reporting a link between dietary sodium and potassium intake with CKD in the general US population. Second, NHANES used uniform methods to collect data on dietary recall, serum creatinine and urinary albumin excretion. Third, the extensive and complete data on other important factors associated with CKD, allowed us to give an unbiased estimate for the relationship between dietary sodium and potassium intake and CKD. Finally, with the design of NHANES, we were able to extrapolate the results to the entire US civilian noninstitutionalized population.

In conclusion, our study shows that higher potassium and sodium intake are independently associated with lower odds of CKD in a nationally representative sample of the US adult population. These findings should be subjected to corroboration through longitudinal studies and clinical trials designed specifically to examine the effects of dietary sodium and potassium intake on kidney disease and its progression.

\section{Disclosure Statement}

Support came from the National Institute of Diabetes and Digestive and Kidney Disease (NIDDK) grants K23 DK08785901A1, RO1 DK 081473 and RO1 DK 078112. All the authors declared no competing interests.

\section{References}

1 Coresh J, Selvin E, Stevens LA, Manzi J, Kusek JW, Eggers P, Van Lente F, Levey AS: Prevalence of chronic kidney disease in the United States. JAMA 2007;298:2038-2047.

-2 Gregg EW, Cheng YJ, Cadwell BL, Imperatore G, Williams DE, Flegal KM, Narayan KM, Williamson DF: Secular trends in cardiovascular disease risk factors according to body mass index in US adults. JAMA 2005;293: 1868-1874.

- 3 Mokdad AH, Ford ES, Bowman BA, Dietz WH, Vinicor F, Bales VS, Marks JS: Prevalence of obesity, diabetes, and obesity-related health risk factors, 2001. JAMA 2003;289:76-79.
-4 de Boer IH, Rue TC, Hall YN, Heagerty PJ, Weiss NS, Himmelfarb J: Temporal trends in the prevalence of diabetic kidney disease in the United States. JAMA 2011;305:25322539.

5 Fields LE, Burt VL, Cutler JA, Hughes J, Roccella EJ, Sorlie P: The burden of adult hypertension in the United States 1999 to 2000: a rising tide. Hypertension 2004; 44 : 398-404.

6 Hajjar I, Kotchen TA: Trends in prevalence, awareness, treatment, and control of hypertension in the United States, 1988-2000. JAMA 2003;290:199-206.
7 Shlipak MG, Fried LF, Cushman M, Manolio TA, Peterson D, Stehman-Breen C, Bleyer A, Newman A, Siscovick D, Psaty B: Cardiovascular mortality risk in chronic kidney disease: comparison of traditional and novel risk factors. JAMA 2005;293:1737-1745.

8 Maschio G, Alberti D, Janin G, Locatelli F, Mann JF, Motolese M, Ponticelli C, Ritz E, Zucchelli P: Effect of the angiotensin-converting-enzyme inhibitor benazepril on the progression of chronic renal insufficiency. The Angiotensin-Converting-Enzyme Inhibition in Progressive Renal Insufficiency Study Group. N Engl J Med 1996;334:939-945. 
9 Ruggenenti P, Perna A, Gherardi G, Garini G, Zoccali C, Salvadori M, Scolari F, Schena FP, Remuzzi G: Renoprotective properties of ACE-inhibition in non-diabetic nephropathies with non-nephrotic proteinuria. Lancet 1999;354:359-364.

10 Lewis EJ, Hunsicker LG, Clarke WR, Berl T, Pohl MA, Lewis JB, Ritz E, Atkins RC, Rohde R, Raz I, Collaborative Study Group: Renoprotective effect of angiotension-receptor antagonist irbesartan in patients with nephropathy due to type 2 diabetes. N Engl J Med 2001; 345:851-860.

11 Lewis EJ, Hunsicker LG, Bain RP, Rohde RD: The effect of angiotensin-converting-enzyme inhibition on diabetic nephropathy. The Collaborative Study Group. N Engl J Med 1993; 329:1456-1462.

12 Appel LJ, Moore TJ, Obarzanek E, Vollmer WM, Svetkey LP, Sacks FM, Bray GA, Vogt TM, Cutler JA, Windhauser MM, Lin PH, Karanja N: A clinical trial of the effects of dietary patterns on blood pressure. DASH Collaborative Research Group. N Engl J Med 1997;336:1117-1124.

13 Levey AS, Coresh J, Greene T, Stevens LA, Zhang YL, Hendriksen S, Kusek JW, Van Lente F, Chronic Kidney Disease Epidemiology Collaboration: Using standardized serum creatinine values in the Modification of Diet in the Renal Disease study equation for estimating glomerular filtration rate. Ann Intern Med 2006;145:247-254.

14 Barton M, Vos I, Shaw S, Boer P, D'Uscio LV, Gröne HJ, Rabelink TJ, Lattmann T, Moreau P, Lüscher TF: Dysfunctional renal nitric oxide synthase as a determinant of salt-sensitive hypertension. J Am Soc Nephrol 2000;11:835-845.

15 Meng S, Roberts LJ 2nd, Cason GW, Curry TS, Manning RD Jr: Superoxide dismutase and oxidative stress in Dahl salt-sensitive and -resistant rats. Am J Physiol Regul Integr Comp Physiol 2002;283:R732-R738.

16 Kitiyakara C, Chabrashvili T, Chen Y Blau J, Karber A, Aslam S, Welch WJ, Wilcox CS: Salt intake, oxidative stress, and renal expression of NADPH oxidase and superoxide dismutase. J Am Soc Nephrol 2003;14:2775-2782.

17 Weir MR, Dengel DR, Behrens MT, Goldberg AP: Salt-induced increases in systolic blood pressure affect renal hemodynamics and proteinuria. Hypertension 1995;25:1339-1344.

18 Suckling RJ, He FJ, MacGregor GA: Altered dietary salt intake for preventing and treating diabetic kidney disease. The Cochrane Library 2010;12:CD006763.
9 Ekinci El, Thomas G, Thomas D, Johnson C, Macisaac RJ, Houlihan CA, Finch S, Panagiotopoulos S, O'Callaghan C, Jerums G: Effects of salt supplementation on the albuminuric response to telmisartan with or without hydrochlorothiazide therapy in hypertensive patients with type 2 diabetes are modulated by habitual dietary salt intake. Diabetes Care 2009;32:1398-1403.

20 Lin J, Hu FB, Curhan GC: Associations of diet with albuminuria and kidney function decline. Clin J Am Soc Nephrol 2010;5:836-843.

21 Lin J, Fung TT, Hu FB, Curhan GC: Association of dietary patterns with albuminuria and kidney function decline in older white women: a subgroup analysis from the Nurses' Health Study. Am J Kidney Dis 2011;57:245-254.

22 Weir MR, Chrysant SG, McCarron DA, Canossa-Terris M, Cohen JD, Gunter PA, Lewin AJ, Mennella RF, Kirkegaard LW, Hamilton $\mathrm{JH}$, et al: Influence of race and dietary salt on the antihypertensive efficacy of an angiotensin-converting enzyme inhibitor or a calcium channel antagonist in salt-sensitive hypertensives. Hypertension 1998;31:10881096.

23 Lambers Heerspink HJ, Holtkamp FA, Parving HH, Navis GJ, Lewis JB, Ritz E, de Graeff PA, de Zeeuw D: Moderation of dietary sodium potentiates the renal and cardiovascular protective effects of angiotensin receptor blockers. Kidney Int 2012;82:330-337.

24 Thomas M, Moran J, Forsblom C, Harjutsalo V, Thorn L, Ahola A, Wadèn J, Tolonen N, Saraheimo M, Gordin D, et al; FinnDiane Study Group: The association between dietary sodium intake, ESRD, and all-cause mortality in patients with type 1 diabetes. $\mathrm{Di}$ abetes Care 2011;34:861-866.

25 Cook NR, Obarzanek E, Cutler JA, Buring JE, Rexrode KM, Kumanyika SK, Appel LJ, Whelton PK, Trials of Hypertension Prevention Collaborative Research Group: Joint effects of sodium and potassium intake on subsequent cardiovascular disease: the Trials of Hypertension Prevention follow-up study. Arch Intern Med 2009;169:32-40.

26 Young DB, Lin H, McCabe RD: Potassium's cardiovascular protective mechanisms. Am J Physiol 1995;268:R825-R837.
27 Intersalt: an international study of electrolyte excretion and blood pressure. Results for $24 \mathrm{~h}$ urinary sodium and potassium excretion. Intersalt Cooperative Research Group. BMJ 1988;297:319-328.

28 Houston MC: The importance of potassium in managing hypertension. Curr Hypertens Rep 2011;13:309-317.

29 Cappuccio FP, MacGregor GA: Does potassium supplementation lower blood pressure? A meta-analysis of published trials. J Hypertens 1991;9:465-473.

30 Whelton PK, He J, Cutler JA, Brancati FL, Appel LJ, Follmann D, Klag MJ: Effects of oral potassium on blood pressure. Meta-analysis of randomized controlled clinical trials. JAMA 1997;277:1624-1632.

31 Dyer AR, Elliott P, Shipley M: Urinary electrolyte excretion in $24 \mathrm{~h}$ and blood pressure in the INTERSALT Study. II. Estimates of electrolyte-blood pressure associations corrected for regression dilution bias. The INTERSALT Cooperative Research Group. Am J Epidemiology 1994;139:940-951.

32 Geleijnse JM, Kok FJ, Grobbee DE: Blood pressure response to changes in sodium and potassium intake: a metaregression analysis of randomized trials. J Hum Hypertens 2003; 17:471-480.

33 Espeland MA, Kumanyika S, Wilson AC, Reboussin DM, Easter L, Self M, Robertson J, Brown WM, McFarlane M, TONE Cooperative Research Group: Statistical issues in analyzing 24-hour dietary recall and 24-hour urine collection data for sodium and potassium intakes. Am J Epidemiol 2001;153:996-1006.

34 Bazzano LA, He J, Ogden LG, Loria C, Vupputuri S, Myers L, Whelton PK: Dietary potassium intake and risk of stroke in US men and women: National Health and Nutrition Examination Survey I epidemiologic followup study. Stroke 2001;32:1473-1480.

35 He J, Ogden LG, Bazzano LA, Vupputuri S, Loria C, Whelton PK: Dietary sodium intake and incidence of congestive heart failure in overweight US men and women: first National Health and Nutrition Examination Survey Epidemiologic Follow-Up Study. Arch Intern Med 2002;162:1619-1624.

-36 Yang Q, Liu T, Kuklina EV, Flanders WD, Hong Y, Gillespie C, Change MH, Gwinn M, Dowling N, Khoury MJ, Hu FB: Sodium and potassium intake and mortality among US adults: prospective data from the Third $\mathrm{Na}-$ tional Health and Nutrition Examination Survey. Arch Intern Med 2011;171:1183-1191. 